\title{
Groundwater Quality in the Columbia Plateau Basaltic-Rock Aquifers, Northwestern United States
}

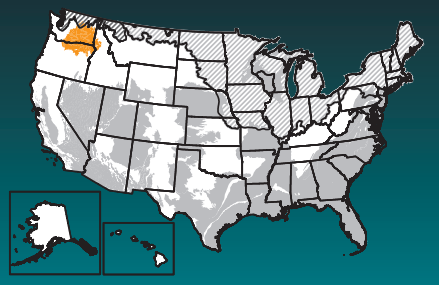

Groundwater provides nearly 50 percent of the Nation's drinking water. To help protect this vital resource, the U.S. Geological Survey (USGS) National Water-Quality Assessment (NAWQA) Project assesses groundwater quality in aquifers that are important sources of drinking water. The Columbia Plateau basaltic-rock aquifers constitute one of the important resources being evaluated.

\section{Background}

The Columbia Plateau basaltic-rock aquifers underlie an area of about 42,000 square miles, which is populated by about a million people in Washington, Oregon, and Idaho. The basaltic-rock aquifers are an important source of groundwater for public supply, ranking 19th in the Nation for this use and providing about 223 million gallons per day (Mgal/d; Maupin and Barber, 2005; Arnold and others, 2020a). Land use overlying the Columbia Plateau basaltic-rock aquifers is primarily natural land cover (64 percent) and agriculture (33 percent) with small amounts of urban and other developed land (4 percent; Homer and others, 2015). Several urban areas - Spokane and the Washington Tri-Cities (Richland, Kennewick, and Pasco) in Washington; and Coeur d'Alene and Lewiston in Idaho- - lie within the aquifer system's overlying land along with dozens of smaller communities.

Most of the Columbia Plateau is semiarid (precipitation ranges from 7 to 15 inches per year in the central part of the plateau), yet the region supports a \$6-billion-per-year agricultural industry, which leads the Nation in production of apples, hops, and several other commodities (Vaccaro and others, 2015). Water demand for agriculture, economic development, and ecological needs in the area is high (Kahle and others, 2011). The plateau accounts for about 7 percent of the Nation's irrigated lands (U.S. Geological Survey, 2014), which are supplied by a combination of groundwater pumping and surface-water diversions.

The Columbia Plateau is an intermontane basin lying between the Cascade Range to the west and the Rocky Mountains to the east that is filled with Neogene basalt and sediment. The primary aquifers in the region are the Miocene-aged continental flood basalts of the Columbia River Basalt Group and, in places, basin-fill sediments, which generally overlie the flood basalts (Vaccaro and others, 2015). Only the basaltic-rock aquifers were sampled for this study. The Columbia Plateau basin-fill aquifers—which rank 67 th in the Nation as a source of groundwater for public supply with less than $1 \mathrm{Mgal} / \mathrm{d}$ pumped for this use in 2000 (Maupin and Barber, 2005; Arnold and others, 2020a) - were not sampled for this study. The Columbia River Basalt Group consists of a series of lava flows that erupted from 17 to 6 million years ago. Individual flows range from 10 to more than 300 feet in thickness, with total thickness of the flows estimated to be at least 14,000 feet in some places (Drost and others, 1990). The basaltic-rock aquifers consist of a series of productive basalt units, the most extensive and thickest of which is the Grande Ronde Basalt, separated by less permeable interbeds that act as confining units along with less permeable flow interiors (Whitehead, 1994; Kahle and others, 2011). Groundwater flow is from topographically high margins of the plateau toward major surface drainages, including the Columbia and Snake Rivers. The Cascade Range in Oregon and Washington is an important recharge area for the western part of the regional aquifer system, and the Rocky Mountains and Blue Mountains (to the southeast) serve as important recharge areas in the eastern and southern extents of the Columbia Plateau, respectively. Locally, groundwater levels in the Columbia Plateau have changed by up to hundreds of feet as a result of irrigation practices, resulting in both increases (from increased recharge from irrigation) and decreases (from increased groundwater pumping)

Groundwater quality in the

Columbia Plateau basaltic-rock aquifers was evaluated in 2016 by sampling 60 public-supply wells that were spatially distributed across the aquifers' area. For this discussion, we define the study area as the depth zone used for public supply in the Columbia Plateau basaltic-rock aquifers. Water-quality data collected from the spatially distributed wells (5 in Idaho, 20 in Oregon, and 35 in Washington) are representative of water quality in the study area, following the approach described by Belitz and others (2010). This approach allows for the estimation of the percentage of the study area with concentrations that are high, moderate, and low with respect to constituent benchmarks. The accuracy of the estimates depends on the distribution and number of wells, not the size of the area (Belitz and others, 2010). The wells ranged from 91 to 2,434 feet deep (averaging 604 feet deep) and were typically open to the aquifer across long depth intervals ranging from 5 to 1,297 feet (averaging about 293 feet). Samples were analyzed for a large number of water-quality constituents derived from natural and human sources.

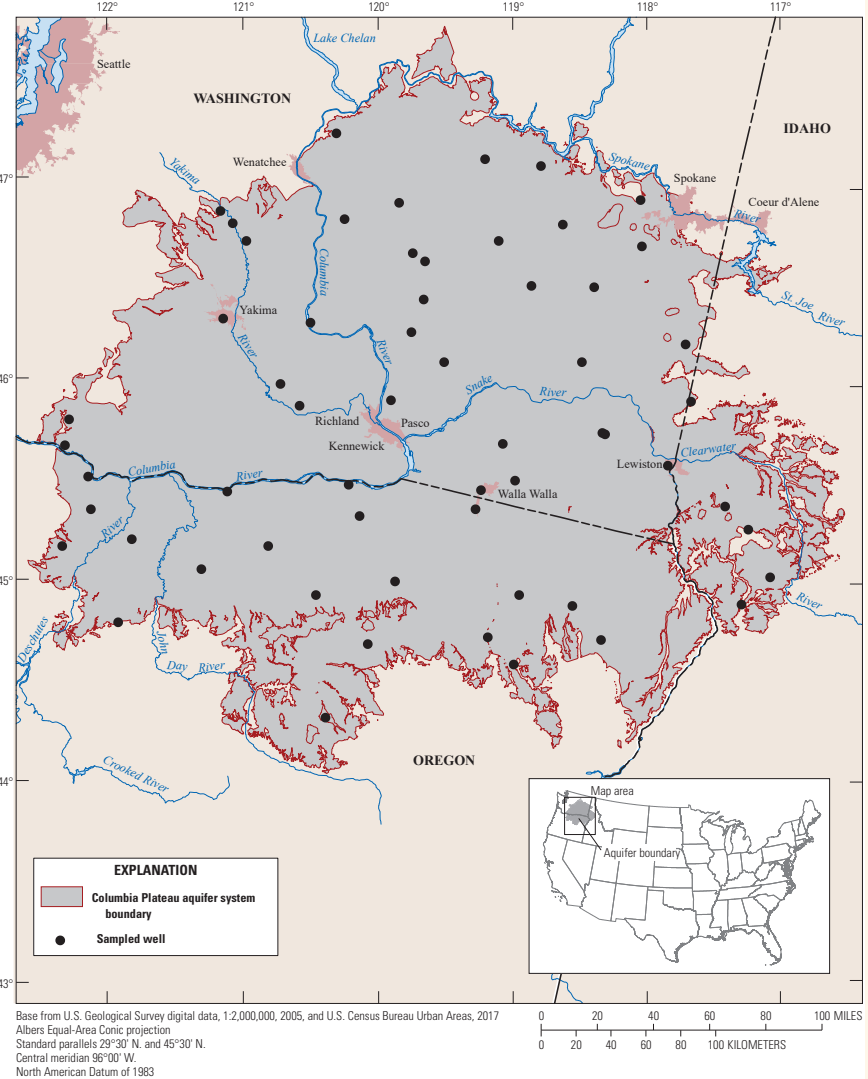

Central meridian $960^{\circ} 0^{\circ}$ ' W.

\section{Overview of Water Quality Inorganic constituents \\ Organic constituents}
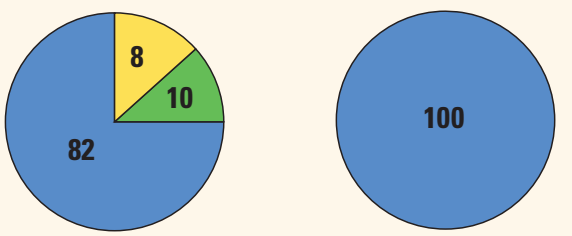

CONSTITUENT CONCENTRATIONS

$\bigcirc$ High $\bigcirc$ Moderate $\bigcirc$ Low or not detected

Values are a percentage of the study area with concentrations in the three specified categories. Percentages might not sum to 100 because of rounding.

Principal Aquifer Studies (Burow and Belitz, 2014) are designed to evaluate groundwater used for public supply prior to any treatment. Groundwater quality is assessed by comparing concentrations to benchmarks established for drinking-water quality. Benchmarks and definitions of high, moderate, and low relative concentrations are discussed at the bottom of page 3 . Water from 92 percent of the wells sampled did not have high concentrations relative to benchmarks of any constituent measured.

Many inorganic constituents are naturally present in groundwater. The concentrations of inorganic constituents can be affected by natural processes as well as by human activities. One or more inorganic constituents with human-health benchmarks were detected at high concentrations in about 8 percent of the study area and at moderate concentrations in about 10 percent.

Organic constituents derived from human activities are used in household, business, industrial, and agricultural products. They can enter the environment through normal usage, spills, or improper disposal. Organic constituents with humanhealth benchmarks were not detected at high or moderate concentrations in the study area. 


\section{Results: Groundwater Quality at the Depth Zone Used for Public Supply in the Columbia Plateau Basaltic-Rock Aquifers}

\section{INORGANIC CONSTITUENTS}
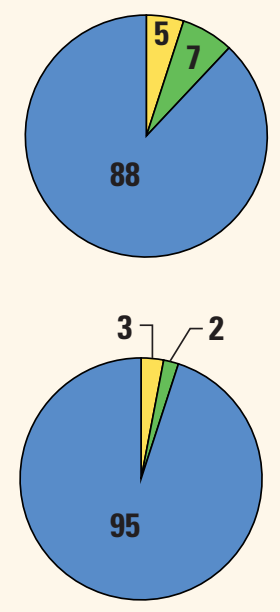

\section{Radioactive constituents}
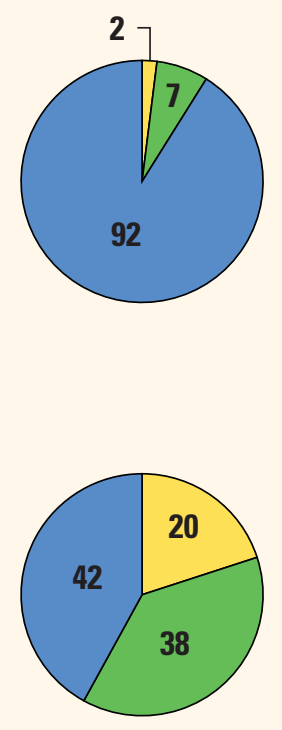

\section{Inorganic Constituents With Human-Health Benchmarks}

Trace elements and major and minor ions are naturally present in the minerals of rocks, soils and sediments, and in the water that comes into contact with those materials. Samples were analyzed for 34 trace elements and major and minor ions, of which 22 have human-health benchmarks (health-based screening level [HBSL] benchmarks were updated in 2018 to include aluminum, cobalt, and iron). Constituents from this group, specifically arsenic, were detected at high concentrations in about 5 percent of the study area (the depth zone used for public supply). Constituents from this group were detected at moderate concentrations in about 7 percent of the study area. Fluoride was the trace element most frequently detected at moderate concentrations (3 percent).

Radioactivity is the release of energy or energetic particles during the spontaneous decay of unstable atoms. Humans are continuously exposed to small amounts of natural radioactivity. Most of the radioactivity in groundwater comes from the decay chain of isotopes of uranium and thorium that are naturally present in minerals in aquifer materials. Samples were analyzed for eight radioactive constituents, of which four have human-health benchmarks. Radioactive constituents were infrequently present at high (3 percent) or moderate ( 2 percent) concentrations in the study area as gross-alpha activity and radon.

Nutrients are naturally present at low concentrations in groundwater; high and moderate concentrations (relative to human-health benchmarks) generally result from human activities. Samples were analyzed for five nutrients, of which two have human-health benchmarks. Common sources of nutrients, aside from soils, include fertilizer applied to crops and landscaping, seepage from septic systems, and human and animal waste. The nutrient nitrate was detected at high or moderate concentrations in about 2 and 7 percent, respectively, of the study area.

\section{Inorganic Constituents and Field Measurements With Non-Health-Based Benchmarks}

(Not included in water-quality overview charts shown on the front page)

Some constituents affect the aesthetic properties of water, such as taste, color, and odor, or can create nuisance problems, such as staining and scaling. The benchmarks used for these constituents were non-regulatory secondary maximum contaminant level (SMCL) benchmarks established for public drinking water. Some constituents, such as manganese and fluoride, have human-health benchmarks and SMCLs. Samples were analyzed for 11 constituents that have SMCLs. One or more of these were present at high concentrations or values relative to the SMCL in about 20 percent of the study area and at moderate concentrations in about 38 percent.

Total dissolved solids (TDS) concentration is a measure of the salinity of the groundwater based primarily on concentrations of ions. All water naturally contains TDS because of the weathering and dissolution of minerals in rocks and sediments. Concentrations of TDS can be high because of natural factors or as a result of human activities, such as applications to the land surface of road salt, fertilizers, or other chemicals in urban or agricultural areas. Much of the study area had high ( 7 percent) or moderate (37 percent) concentrations of TDS. Fluoride was present at high concentrations in about 3 percent of the study area and at moderate concentrations in about 8 percent, respectively. Sulfate was also present at high or moderate concentrations in about 5 percent of the study area.

Anoxic conditions in groundwater (low amounts of dissolved oxygen) can result in the release of iron and manganese in minerals to the groundwater. Manganese was present at high concentrations relative to the SMCL in about 10 percent of the study area and at moderate concentrations in about 13 percent. Iron was present at high or moderate concentrations relative to the SMCL in about 10 percent of the study area.

In some areas of the Columbia Plateau basaltic-rock aquifers, the $\mathrm{pH}$ of the groundwater exceeded the SMCL range of 6.5 to 8.5 . The $\mathrm{pH}$ was greater than 8.5 , which is alkaline, in about 7 percent of the study area. 


\section{Results: Groundwater Quality at the Depth Zone Used for Public Supply in the Columbia Plateau Basaltic-Rock Aquifers}

\section{ORGANIC CONSTITUENTS}

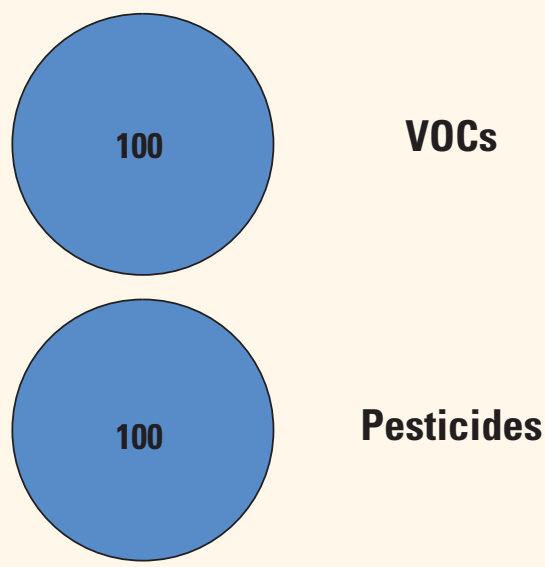

\section{Volatile Organic Compounds With Human-Health Benchmarks}

Volatile organic compounds (VOCs) are present in many household, commercial, industrial, and agricultural products and are characterized by their tendency to volatilize (evaporate). Samples were analyzed for 85 VOCs, of which 51 have human-health benchmarks. No VOCs were detected at high or moderate concentrations in the study area.

\section{Pesticides With Human-Health Benchmarks}

Pesticides, including herbicides, insecticides, and fungicides, are applied to crops, gardens and lawns, around buildings, and along roadways to help control unwanted vegetation (weeds), insects, fungi, and other pests. Samples were analyzed for 225 pesticide compounds (pesticides and their breakdown products), of which 119 have human-health benchmarks. Pesticide compounds were not detected at high or moderate concentrations in the study area.

\section{BENCHMARKS FOR EVALUATING GROUNDWATER QUALITY}

The USGS NAWQA Project uses benchmarks established for drinking water to provide context for evaluating the quality of untreated groundwater. The quality of water received by consumers can be different from results presented herein because after withdrawal, groundwater may be treated prior to delivery. Federal regulatory benchmarks for protecting human health are used for this evaluation of water quality when available. Otherwise, nonregulatory human-health benchmarks and non-regulatory aesthetic benchmarks are used. Not all constituents analyzed have benchmarks and, thus, are not considered in this context. Human-health benchmarks are available for 28 of 55 inorganic constituents and properties and 170 of 310 organic constituents.

Concentrations are considered high if they are greater than a human-health benchmark (Norman and others, 2018) or SMCL. For inorganic constituents, concentrations are moderate if they are greater than one-half of a benchmark. For organic constituents, concentrations are moderate if they are greater than one-tenth of a benchmark; this lower threshold is used because organic constituents are generally less prevalent and have smaller concentrations relative to benchmarks than inorganic constituents (Toccalino and others, 2004).

\section{Benchmark Type and Value for Selected Constituents}

This table presents benchmarks for those constituents detected at high concentrations in the Columbia Plateau basaltic-rock aquifers. Benchmark types are regulatory U.S. Environmental Protection Agency (EPA) maximum contaminant levels (MCLs), nonregulatory health-based screening levels (HBSLs), and non-regulatory EPA secondary maximum contaminant levels (SMCLs).

[ppb, part per billion or microgram per liter $(\mu \mathrm{g} / \mathrm{L})$; ppm, part per million or milligram per liter $(\mathrm{mg} / \mathrm{L})$; pCi/L, picocurie per liter]

\begin{tabular}{|c|c|c|c|c|c|}
\hline \multirow{2}{*}{ Constituent } & \multicolumn{2}{|c|}{ Benchmark } & \multirow{2}{*}{ Constituent } & \multicolumn{2}{|c|}{ Benchmark } \\
\hline & Type & Value & & Type & Value \\
\hline Arsenic & MCL & $10 \mathrm{ppb}$ & Total dissolved solids (TDS) & SMCL & $500 \mathrm{ppm}$ \\
\hline Nitrate as nitrogen & MCL & $10 \mathrm{ppm}$ & Fluoride & SMCL & $2 \mathrm{ppm}$ \\
\hline Gross-alpha activity & MCL & $15 \mathrm{pCi} / \mathrm{L}$ & Sulfate & SMCL & $250 \mathrm{ppm}$ \\
\hline \multirow[t]{3}{*}{ Radon-222 } & HBSL & $4,000 \mathrm{pCi} / \mathrm{L}$ & Iron & SMCL & $300 \mathrm{ppm}$ \\
\hline & & & Manganese & SMCL & $50 \mathrm{ppb}$ \\
\hline & & & $\mathrm{pH}$ & SMCL & $6.5-8.5$ \\
\hline
\end{tabular}




\section{Constituents With High Concentration Vary Spatially}

Inorganic constituents with healthbased benchmarks were present at high or moderate concentrations in only about 8 and 10 percent of the study area, respectively. The distribution of samples with moderate and high concentrations varied across the study area with most in Washington and Idaho. Only one sample in Oregon exceeded a health-based benchmark for an inorganic constituent. Constituents with secondary, non-health-based benchmarks were detected at high or moderate concentrations (20 and 38 percent, respectively) more frequently than constituents with health-based benchmarks. Similar to constituents with health-based benchmarks, high concentrations of constituents with secondary, non-health-based benchmarks were more common in the northern, central, and eastern parts of the aquifer in Washington and Idaho. A previous assessment of water quality in the Columbia Plateau basalticrock aquifers noted vulnerability to contaminants resulting from intensive agriculture, such as nitrate, as well as naturally occurring constituents, which were greatest in the shallower parts of the aquifer (Frans and others, 2012).

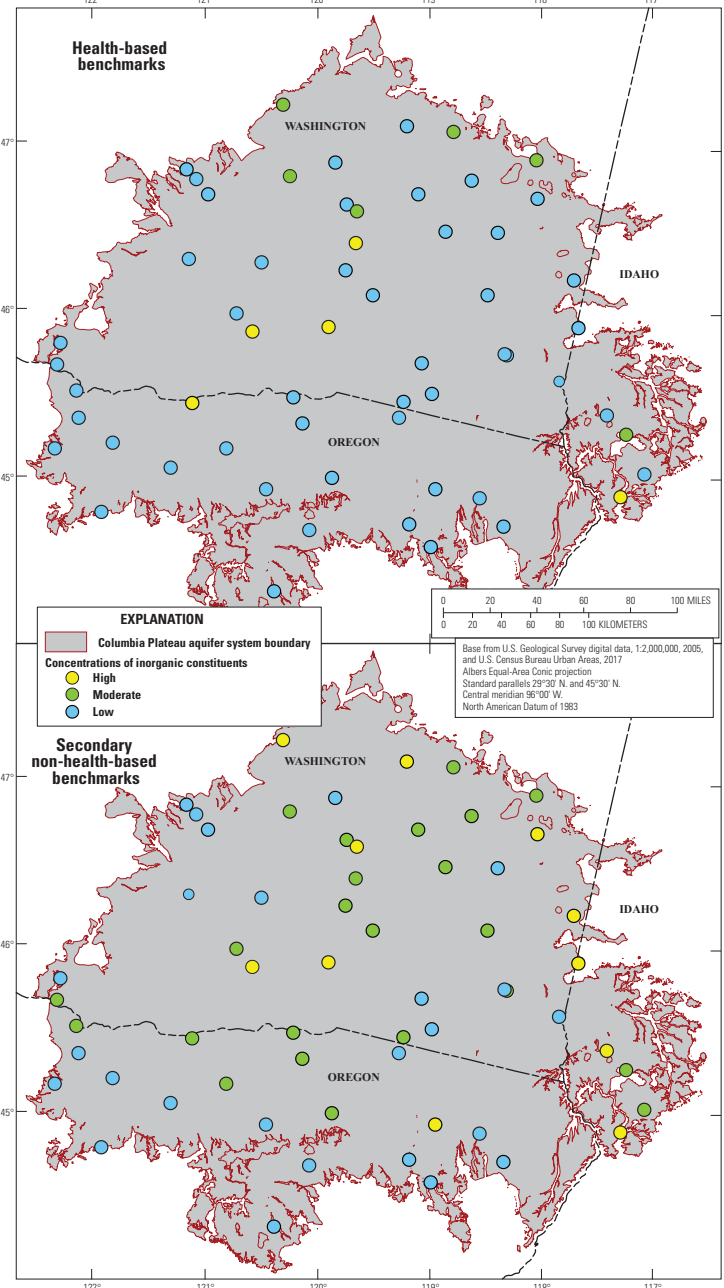

By MaryLynn Musgrove

\section{Principal Aquifer Studies}

The USGS NAWQA Project has been assessing the quality of groundwater since 1991. The NAWQA studies include Land Use Studies (LUS), Major Aquifer Studies (MAS), and Principal Aquifer Studies (PAS). These three study types are based on sampling networks of wells distributed across an area of interest. The LUS networks typically consist of observation wells that are relatively shallow; MAS networks typically consist of domestic-supply wells that are intermediate in depth; and PAS networks typically consist of publicsupply wells that are relatively deep. A national synthesis of shallow and intermediate depth groundwater quality was reported by DeSimone and others (2014). A regional synthesis of water quality for basin-fill and basaltic-rock aquifers that includes the Columbia Plateau basaltic-rock aquifers was reported by Rupert and others (2014). This fact sheet provides a summary of PAS data for 60 public-supply wells sampled in 2016 in the Columbia Plateau basaltic-rock aquifers (data available in Arnold and others, 2020b).

The PAS assessments like this one allow for the comparison of constituent concentrations in untreated groundwater with benchmarks established for the protection of human health and for aesthetic qualities of drinking water and also provide a basis for comparison of groundwater quality among the principal aquifers.

The data collected by the NAWQA Project include chemical analyses generally not available as part of regulatory compliance monitoring, including measurements at concentrations much lower than the levels used as human-health benchmarks and measurement of constituents that can be used to trace the sources and movement of groundwater.

\section{For more information}

Technical reports and hydrologic data collected for the USGS NAWQA Project may be obtained from:

\section{NAWQA Chief Scientist}

U.S. Geological Survey

12201 Sunrise Valley Drive, MS 413

Reston, VA 20192-0002

Email: nawqapublicinfo@usgs.gov

WEB: https://water.usgs.gov/nawqa/

ISSN 2327-6916 (print)

ISSN 2327-6932 (online)

https://doi.org/10.3133/fs20193058 